\title{
Influences on the Diffusion of Environmental Programmes in Small Businesses in the Greening of an Industry for Sustainability: The Case of Golf
}

\author{
Dino M. Minoli ${ }^{1}$ \\ ${ }^{1}$ Independent Sustainability Consultant, Wales, UK \\ Correspondence: Dino Minoli, Independent Sustainability Consultant, Flat 2, Mona Lodge, Maryport Street, Usk, \\ UK. NP15 1ED.
}

Received: May 2, 2018 Accepted: May 13, 2018 Online Published: May 14, 2018

doi:10.5539/jms.v8n2p1ＵRL: https://doi.org/10.5539/jms.v8n2p1

\begin{abstract}
Globally there are around 34,000 golf facilities including very many small golf clubs that collectively generate significant economic, social and environmental impacts. Thus, small golf clubs have an important role to play in the greening of golf in support of sustainability. Environmental programmes (EPs) were developed to improve the environmental performance of all types and sizes of golf facilities. However, EPs are rarely employed in small golf clubs and no research until now has explored the reasons for this. Data from an in-depth mixed methods case study found several internal and external influences on the level of implementation of EPs in small golf clubs. Interventions are suggested to stimulate the uptake of EPs in smaller golf clubs. The study is of value to the golf sector, government policy and organisations concerned with the greening of small businesses in the greening of an industry sector for sustainability. The study also provides a conceptual/empirical framework for further studies in this under-researched yet noteworthy field.
\end{abstract}

Keywords: environmental programmes, small businesses, greening of industry, sustainability, small golf clubs

\section{Introduction}

Worldwide there are an estimated 34,000 golf facilities (The Royal and Ancient Golf Club of St Andrews [R\&A], 2015). Moreover, a significant number of them are small golf clubs that taken together create important economic (e.g., Sport Research Industry Centre, 2016), social (e.g., Kishimoto et al., 2016; Reid \& Hunter, 2013) and environmental impacts (e.g., Colding \& Folke, 2009). Consequently, small golf clubs have a significant part to play in progressing sustainable golf in support of sustainable golf sport, tourism and leisure. Sustainable golf is defined as 'optimising the playing quality of the golf course in harmony with the conservation of its natural environment under economically sound and socially responsible management' (R\&A, 2017).

Environmental programmes (EPs) were developed to continually improve the environmental performance of all types and sizes of golf facilities in all geographies (International Standardisation Organisation [ISO], 2015). However, at present, small golf clubs seldom implement EPs and so far no research has explored why this is the case (Minoli \& Smith, 2011). Thus, the study's main aim is to investigate and identify the influences on the level of implementation of EPs in small golf clubs and to inform and put forward interventions to catalyse small golf clubs to join EPs.

The study's data comes from an in-depth, exploratory mixed methods case study. This includes the 'Theory of Planned Behaviour' (Ajzen, 1991) and a model (e.g. Schaper, 2001), meta-analyses (e.g. Johnson \& Schaltegger, 2016; Parker, Redmond, \& Simpson, 2009) and studies (e.g. Hillary \& Burr, 2011; McKeiver \& Gadenne, 2005; Federation of Small Businesses, 2007; Hillary, 2004) of the influences on the level of implementation of EPs in small businesses. These data are used as a conceptual/empirical framework to explore the study's topic. In addition, the study contains the findings of interviews and results of surveys that consider small golf clubs' actual opinion on the potential employment of EPs. Further, interventions put forward in the paper's Discussion to increase the uptake of EPs in small golf clubs are in part based on Kotter's (2012) influential change management model and Spence and Rinaldi's (2010) work on embedding sustainability within an industry's stakeholders and supply chain. Also, the study's focal point is Wales, the UK. In view of the fact that Wales is one of the first countries in the world to have a legal duty to develop and support sustainability (Welsh Assembly 
Government, 2009) and nearly all of its 175 golf clubs are small businesses (Welsh Golf Union, 2016). The study also focuses on the Golf Environment Organisation (GEO) OnCourse ${ }^{\circledR}$. Since it is a leading, well-regarded global EP that is applicable to all types and sizes of golf facilities (ISEAL Alliance, 2017; Russell, 2015).

What is more, this situation presents Wales (and other similar countries and regions) with an opportunity to be a 'pathfinder' in, for example, green golf destinations within sustainable golf sport, tourism and leisure (Peattie, 2005, p. 9). Also, credible EPs could provide golf facilities and golf destinations with a comparably more efficient, better value, higher quality, more responsible and progressive and hence premium golf product that may well give rise to a 'competitive advantage' (Porter, 1998). However, this in part requires small golf clubs to implement EPs and for that reason, it is important to determine the factors that influence their uptake. As interventions can then be developed and implemented to drive and overcome any apparent obstacles that hinder the wider diffusion of EPs in this important sector of the global economy.

Overall, the study found several external and internal influences on the level of implementation of EPs in small golf clubs. From this, a series of interventions are accordingly suggested to help drive the uptake of EPs in small golf clubs. The study's findings should be of value to the golf sector in progressing more sustainable golf and also public policy and organisations concerned with the influences on the level of implementation of EPs in smaller businesses. Given that the greening of small businesses supports the greening of an industry sector for sustainability (The Greening of Industry Network, 2018; United Nations Industrial Development Organisation [UNIDO], 2011; Schot, Brand, \& Fisher, 1997). The novel study also offers a constructive conceptual/empirical framework and an initial insight into this much under-researched yet significant area of study. Having introduced the paper the next sections of the paper continue with the literature review, methods, findings and results and conclusions, in that order.

\section{Literature Review}

\subsection{EPs: A Tool to Progress the Greening of Golf Clubs for Sustainable Golf in Support of Sustainability}

EPs are an example of a voluntary, market-based tool that was developed to enable businesses and industries, demonstrate continuous improvement in their environmental performance, beyond that which is required by the environmental regulatory system (Darnell \& Sides, In deLeon and Rivera, 2010, p. 214). In practice, EPs help businesses identify, manage, monitor and control their environmental issues in a holistic manner (ISO, 2015). In so doing, businesses use resources more efficiently, reduce waste, and gain a competitive advantage and stakeholders' trust (ISO, 2015). EPs can be sub-divided into formal and informal programmes. Formal EPs commonly take in a number of management system stages to formalise the businesses policies, procedures, and practices that control the environmental impacts of businesses (Hillary, 2004, p. 562). Businesses with formal EPs would be expected to engage in any of the following activities (Mckeiver \& Gadenne, 2005, p. 519). Including:

- Conducting an energy audit and/or environmental audit;

- Using outside advisors to help improve environmental performance;

- Having a written environmental policy;

- Subscribing to a formal environmental certification programme;

- Making specific staff responsible for environmental activities;

- Entailing environmental activities and impacts in the businesses' strategy, mission statement and business plan; and

- Ensuring that the business is complying with all relevant laws and regulations.

Informal EPs refer to what businesses do regarding a number of environmental activities (Mckeiver and Gadenne, 2005: 514). Including:

- Changing business processes to reduce waste and raw materials consumed;

- Conducting staff training on environmental issues;

- Incorporating environmental messages in product marketing or packaging;

- Reducing the amount of packaging used in the products sold;

- Contributing (money or in kind) to environmental activities in the community and environmental organisations; and

- Using recycled packaging in the products sold. 


\subsection{Types of EPs in Golf}

Two types of EP are evident in golf, namely, generic and bespoke EPs (Minoli \& Smith, 2011, p. 880). Generic EPs are applicable for all organisations, regardless of size, industry activity or geography. A well-established EP is the International Standardisation Organisation's (ISO) environmental standard ISO 14001, which was developed in Europe in 1996. An estimated 100-200 worldwide golf clubs have implemented this EP. In addition, there are bespoke EPs that were designed with a specific industry sector in mind, such as golf. Leading examples include the US Audubon Co-operative Sanctuary Programme (ACSP), Australia E-par and UK Golf Environment Organisation (GEO) OnCourse ${ }^{\circledR}$. These programmes have been running since, 1985, 2009 and 2006, respectively. The ACSP has around 2000 golf facility members and both E-Par and GEO OnCourse ${ }^{\circledR}$ have about 1000 golf facility members. In total, approximately $5100(15 \%)$ of the total number of worldwide golf facilities have implemented some type of EP and this is a trend that is likely to continue. In view of the fact that golf facilities are witnessing increasing green 'strategic' pressures, such as, political, economic, social, technological, environmental and legislative, to improve their environmental performance (Minoli \& Smith, 2011, pp. 873-877). However, thus far this development is not really apparent in the very many worldwide small golf facilities. A case in point is GEO OnCourse $@$ and UK small golf clubs.

\subsection{GEO OnCourse ${ }^{\circledR}$ and UK Golf Clubs}

Table 1. GEO OnCourse ${ }^{\circledR}$ and UK golf clubs

\begin{tabular}{|c|c|c|c|c|c|c|c|c|}
\hline \multirow[b]{3}{*}{ Countries } & \multirow[b]{3}{*}{ Golf clubs } & \multirow[b]{3}{*}{$\%$} & \multicolumn{6}{|c|}{ GEO OnCourse ${ }^{\circledR}$} \\
\hline & & & \multicolumn{2}{|c|}{ Registrations (1) } & \multicolumn{2}{|c|}{ Certifications (2) } & \multicolumn{2}{|c|}{$(1)+(2)$} \\
\hline & & & No. & $\%$ & No. & $\%$ & No. & $\%$ \\
\hline England & 2,100 & 70 & 78 & 3.7 & 27 & 1.2 & 105 & 5.0 \\
\hline Scotland & 630 & 21 & 24 & 3.8 & 16 & 2.5 & 40 & 6.3 \\
\hline Wales & 180 & 6 & 9 & 5.0 & 0 & 0.0 & 9 & 5.0 \\
\hline N. Ireland & 90 & 3 & 4 & 4.4 & 1 & 1.1 & 5 & 5.5 \\
\hline Totals & 3,000 & 100 & 115 & 3.8 & 44 & 1.4 & 159 & 5.3 \\
\hline
\end{tabular}

Source: GEO (2017a) and Sport Industry Research Centre (2016).

Table 1 shows the level of implementation of GEO OnCourse ${ }^{\circledR}$ in UK golf clubs. The UK has 3,000 golf clubs of which $115(3.8 \%)$ and $44(1.2 \%)$ are registered and certified to GEO OnCourse ${ }^{\circledR}$, respectively. In total, 159 (5.3\%) UK golf clubs are registered and certified to the above-mentioned EP. Moreover, 10 (23\%) and 34 (77\%) out of the 44 GEO certified UK golf clubs either host the Open Golf Championship and/or are mostly larger/up-market golf facilities, respectively. There is little, if any, uptake of this programme in the very many small UK golf clubs. For example, as mentioned practically all of Wales' golf clubs are small businesses and so far none of them has been certified to GEO OnCourse ${ }^{\circledR}$ or any other EP for that matter.

So what explains this situation? This question is investigated in the next two sections of the paper by means of the 'Theory of Planned Behaviour' and a model, meta-analyses and studies of the influences on the level of implementation of EPs in small businesses.

\subsection{Theoretical Influences on the Level of Implementation of EPs in Small Businesses}

\subsubsection{Theory of Planned Behaviour}

Table 2. Theory of planned behaviour

\begin{tabular}{ccc}
\hline & Behaviour: \\
& small businesses' implement EPs & \\
\hline & Intention: & \\
& small businesses' plan to implement EPs & Norms: \\
\hline Attitudes: & Locus of control: & small businesses' stakeholder views on EPs \\
small businesses & small businesses' capacity to implement & \\
views on EPs & EPs & \\
\hline
\end{tabular}

Source: adapted from Ajzen (1991). 
Table 2 shows the 'Theory of Planned Behaviour' (Ajzen, 1991). It demonstrates that behaviour is dependent on intention, which is dependent upon attitudes, a locus of control and norms. For example, small businesses' behaviour to implement EPs is dependent upon their intention (or plan) to implement EPs. An intention, in turn, is dependent upon small businesses' attitudes on EPs, specifically, their evaluation on whether the benefits of EPs out way their costs. Similarly, small businesses' locus of control (or capacity) which refers to how easy or difficult it is to implement EPs will further influence small businesses' decision to join an EP. This, in turn, is based on an evaluation of the likely costs (i.e. money, time and expertise) required to implement EPs. In addition, norms, namely, small businesses' views on whether their stakeholders, primarily, customers and secondarily, business clients, local community and regulators, would approve or disapprove of them implementing EPs will also influence their decision to join EPs.

Therefore, small businesses that participate in EPs will tend to be those that have positive attitudes, capacity (i.e. time, money and skills) and customer demand for such programmes. Conversely, small businesses that do not tend to join EPs are likely to have negative attitudes, lack of capacity and low customer demand for EPs.

2.4.2 A Model of Influences on the Level of Implementation of EPs in Small Businesses

Table 3. Influences on the level of implementation of EPs in small businesses

\begin{tabular}{ll}
\hline External influences & Internal influences \\
\hline Customers & Owner/manager attitudes \\
Suppliers & Awareness and concern of environmental impact, \\
Legislation & Benefits of implementing an EP \\
& Employee concerns \\
\hline Moderating variables & Moderating variables \\
\hline Type of industry and Size of business & Lack of time \\
& Lack of information \\
& Lack of financial resources \\
& Owner/manager characteristics \\
\hline
\end{tabular}

Source: adapted from Schaper (2001).

Table 3 shows the model of influences on the level of EP implementation in small businesses (Schaper, 2001). It shows that small businesses' instigation of EPs depends on external and internal influences and moderating variables (McKeiver \& Gadenne, 2005, p. 517). External influences comprise owner-managers who believe that environmental issues affect the buying decisions of customers, are important to suppliers, environmental legislation is relevant to their business, and environmental issues are a concern to the local community. Small businesses with these influences would be expected to join EPs.

Internal influences consist of owner-managers who have positive environmental attitudes, a high awareness of environmental outcomes, believe that there are benefits associated with EPs and think environmental issues are of concern to their employees. Small businesses with these influences would also be expected to participate in EPs.

External influences are affected by moderating variables such as the type of industry and size of the business. For example, large manufacturing businesses would be expected to have a higher level of implementation of EPs in comparison to small retail businesses. Similarly, internal influences are affected by moderating variables such as lack of time, information and financial resources and owner/manager characteristics.

Thus, small businesses with owner-managers who believe that they do not have the time, information or resources to address environmental issues are unlikely to join EPs. Equally, small businesses with owner-managers that are younger, and/or female managers, and/or highly educated are more likely to have a relatively higher level of EP participation. There are also a number of practical reasons for small businesses to join EPs that are next discussed.

\subsection{Meta Analyses of Influences on the Level of Implementation of EPs in Small Businesses}

\subsubsection{Reasons for Small Businesses to Implement EPs}

In general, small businesses tend to implement EPs for two main reasons (Hillary \& Burr, 2011, pp. 13-16). (1) To capture business benefits including energy and resource saving, legal compliance, cost reduction, increased market opportunities, improved environmental performance and access to funding. (2) To realise social benefits including improved employee participation and motivation and improved stakeholder relationship. A further key 
driver for small businesses to implement EPs is the perceived improvement to their reputation (Hillary \& Burr, 2011, pp. 13-16).

Further explanations on why EPs should be employed in smaller businesses include the following points (Johnson \& Schaltegger, 2016, pp. 488-494).

- To certify correct environmental legal compliance, gain lower insurance costs through risk management and avoid future costs from noncompliance.

- To improve communications with stakeholders, and develop better relationships with regulators and local community groups.

- To break down the difficulties of environmental sustainability on a business level and make it possible to measure the environmental performance of a small business.

- To aid managers' evaluation of environmental impacts and make appropriate decisions with this obtained information.

- To improve environmental performance through new environmental performance indicators enhanced internal communication and, better overall awareness and understanding of business impacts on the environment and society.

- To put into practice environmental sustainability strategies through systematic approaches to implementing environmental systems into a business organisation.

- To implement an environmental policy that can aid businesses in organisational learning and foster innovation for sustainable products and services.

- To meet the demands of regulatory bodies for environmental protection, waste elimination and health and safety standards.

- To meet the demands of larger businesses that have mandated their small business suppliers adopt an EP as a precondition to doing business.

- To participate in industry networks, business clusters and strategic alliances and therein to share knowledge and resources to allow its members to instigate and maintain an EP.

Another important reason affecting the implementation of EPs in small business is the personal views and beliefs of owner-managers since they are a key motivation for undertaking environmental activities (Federation of Small Businesses, 2007). In particular, in the following order of importance, owner-managers are motivated to implement EPs for reasons associated with good business practices, commitment to reducing their environmental impact and for public relation benefits of demonstrating environmental responsibility. However, while there are valid reasons (or necessary conditions) for small businesses to implement EPs there are also a number of factors that prevent them from doing so that are next discussed.

2.5.2 Barriers, Internal and External Shortcomings and Drivers Affecting the Implementation of EPs in Small Businesses

The most common barrier affecting the implementation of EPs in small business is the cost of implementation (Hillary and Burr, 2011: 13-16). Other important barriers include the lack of skills, knowledge and expertise in the small businesses to implement and maintain an EP and the cost of registration. Moreover, the costs associated with implementation and third-party certification are the greatest barriers for micro and small businesses (Federation of Small Businesses, 2007). Indeed, cost, lack of time, red tape and size of business are important factors that prevent small businesses' greater involvement in EPs (Federation of Small Businesses, 2007). Other reasons for explaining the rare employment of EPs in small businesses can be broken down into internal shortcomings and external deficiencies (Johnson and Schaltegger, 2016).

Internal shortcomings include the fact that small businesses are often unaware of their environmental impacts. Consequently, they do not employ any strategies, plans or tools to rectify unrealised problems. They also see themselves as exempt from sustainability issues due to their perception of having minimal environmental impacts. They also perceive significantly fewer benefits of engagement in environmental issues compared to larger businesses. In addition, they do not realise that many opportunities and programmes are available to educate and support them on environmental issues. They also lack knowledge and expertise on environmental sustainability issues and owner-managers have an inexperienced view on the environmental impacts of their businesses.

What is more, even if small businesses become aware of their environmental impacts and possible benefits of 
EPs, they still lack the expertise to properly deal with these issues. Small businesses also adopt reactive strategies to developing environmental issues that are not embedded into their core long-term business strategy. A shortage of human and financial resources and time constraints further hinder small businesses' implementation of EPs. Also, small businesses' owners and employees are usually responsible or at least involved in more than one business function and so time constraints is a major obstacle in operating an EP.

A number of external deficiencies also impede small businesses' implementation of EPs. First, there are insufficient external government drivers and market incentives, and they are seen as major hindrances for smaller businesses to join EPs. There is also low regulatory pressure and/or low customer demand to adopt EPs. As a result, smaller businesses believe that EPs have little relevance to them. Additionally, the unsuitability of EPs is a further problem. This is because there is an inappropriate fit between formal tools and standards, and informal, flexible smaller business structures and culture. Also, EPs can be expensive and time-consuming to implement and maintain within smaller businesses and for some, they are seen as being too administratively burdensome. The complexity of EPs is a further barrier towards their implementation in smaller businesses.

Moreover, smaller businesses mostly act on a local level, whereas most EPs were developed to account for national and international issues, usually stemming from the impacts of large companies. What is more, given that small businesses include medium, small and micro-sized businesses, it is cumbersome to propose the universal application of EPs to such a diverse group. Thus, a mismatch exists between the generality of EPs in research and the heterogeneity of smaller businesses in practice. This would suggest a diverse set of more size and sector-specific EPs.

What is more, smaller businesses are expected to engage in EPs to the same extent as larger businesses despite the fact that they have very limited and much fewer resources at their disposal to achieve this end. Also, EP certification costs are often the same for all businesses regardless of the size of turnover and there is very limited, if any, public and business support to create a level playing field on the implementation of EP in businesses. Consequently, implementation of EPs is often too huge a challenge for small businesses that result in a low uptake of EPs.

Other drivers influencing the level of implementation of EPs in small businesses includes the following seven factors (Parker, Redmond, \& Simpson, 2009: 5-6).

1) Regulations: the extent to which regulations exist, are extensive enough and enforced on small businesses to implement environmental improvement.

2) Environmental commitment: the degree in which smaller businesses believe they have an environmental impact and responsibility to engage in environmental improvement.

3) Business performance commitment: the amount over which the cost for environmental improvement is exceeded by the short-term economic benefits and competitive advantage for the business.

4) Financial incentives: the level at which financial support is provided to offset the costs or increase the short-term benefits of environmental improvement, or taxes/charges/fines are introduced to discourage negative environmental impact by making it financially unattractive.

5) External demand: the degree under which customers demand environmental improvement of their suppliers, products or services with reduced negative environmental impact, and are willing to pay for this. This, in turn, influences small businesses' perception of the potential for image enhancement, competitive advantage and new business opportunities.

6) Small businesses' environmental knowledge: the level about which small businesses have knowledge on how to engage in environmental improvement and the time to acquire this knowledge.

7) Assistance/education: the degree to which a small business has easy access to assistance and education programmes on how to engage in environmental improvement.

Thus far, the paper has analysed the influences on the level of implementation of EPs in small businesses, based on a review of the literature. It is reasonable to assume that these influences will also apply regarding the degree of employment of EPs in small golf clubs. Given that they too are small businesses. Notwithstanding that and to validate if this is the case, interviews and surveys were conducted with small golf clubs to obtain their views on the possible implementation of EPs. The findings and results from that are presented after the next section on the study's research methods.

\section{Methods}

From 2014 to 2017, an in-depth exploratory, mixed methods case study (Yin, 1984) was conducted to investigate 
the influences on the level of implementation of EPs in small golf clubs. The case study's data came from secondary and primary sources. The secondary data included a theory, model and meta-analyses on the study's topic. The empirical data contained four case units of analysis. They were semi-structured interviews $(n=4)$, survey questionnaire $(n=20)$, focus group interviews $(n=5)$ and survey questionnaire $(n=63)$. The study's participants comprised managers, secretaries, greenkeepers, committee members and golf professionals of small golf clubs. Also, small golf clubs were chosen only if they had less than 10 full-time employees and a turnover under $£ 2$ million (Company Warehouse, 2016; Welsh Golf Union, 2016). The empirical data was collected using self-administered, delivery and collection questionnaires and semi-structured interviews. Likert Scales were used to rate small golf clubs' level of awareness of their environmental performance and EPs and concern on environmental performance. In addition, a multiple choice survey question was used to obtain the main reasons for small golf clubs lack of implementation of EPs. The collected data was analysed using content analysis, coding, pattern matching, interview extracts, tables and bar plots. Four checks were carried out to support the study's validity. (1) A suitable research method was employed, namely, a case study. (2) Survey questionnaires were piloted and steps were taken to guard against interviewer bias, such as allowing the interviewee to discuss the topic in his/her own words. (3) Open questions and in-depth interviewing were used to increase the researcher's chances of understanding the participants' way of thinking on the study's topic. (4) Triangulating evidence from the desk study and case units were used to cross-examine interpretations and reduce the risk of chance associations.

\section{Interview Findings of Influences on the Level of Implementation of EPs in Small Golf Clubs}

\subsection{External Influences}

\subsubsection{Customers of Small Golf Clubs: Members and Visitors}

The first very important factor to explain the current low level of implementation of EPs in small golf clubs is that there is a lack of external pressure from golfers i.e. club members and visitors to encourage, support and give confidence to small golf clubs that they should commit resources for the instigation of EPs. This is illustrated in the following interview extracts:

I think environmental issues are very important...but...less than $10 \%$ of golf members would be concerned about this....all they think of are: availability of tee-times, the condition of the course and annual cost.

Anything that has a direct benefit to the golf course we will get into, but it has to have a benefit...but I personally perceive no benefit from saying that we are part of an EP. I don't think it's any more likely to make Eddie more likely to come and play my golf course or to drink another cup of tea when he's here, and the bottom line is that golf courses need revenue to cover their costs to be able to provide access to that beautiful environment.

(Golfers are) not going to choose to play here over (another golf club) because we've got an eco-label.

\subsubsection{Golf's Stakeholders}

Another factor or driver that is indeed influencing the uptake of EPs in small golf clubs is golf's governing body, the R\&A. Specifically, the R\&A now requires a small number of high-status golf clubs in Wales and the rest of the UK, for example, to be certified to GEO OnCourse ${ }^{\circledR}$, given that this is now a condition for a golf club to host its international, professional and amateur golf tournaments. This is illustrated in the next interview excerpt:

As you are probably aware...(our golf club) has been selected to host the...Boys Home Internationals. With

this, the Club has also been set a deadline to become GEO accredited to be able to host the event.

However, the Welsh Golf Union does not have a strong influence on the implementation of EPs in small golf clubs, since, its Internet website does not explicitly mention sustainable golf and GEO OnCourse ${ }^{\circledR}$ (Welsh Golf Union, 2017). Also, some small golf clubs feel that the Welsh Golf Union is not communicating on EPs, according to the next interview extract:

The GUW don't filter (EPs) down through the clubs. Why aren't they filtering (EPs) down to us?

What is more, small golf clubs' suppliers, regulators and the local community do not appear to have a great deal of influence on the implementation of EPs in small golf clubs, since this was not really mentioned in the interviews with owner/managers within small golf clubs.

\subsection{Internal Influences}

\subsubsection{Owner-Manager Attitudes}

A further factor affecting the implementation of EPs in small golf clubs are owner-manager attitudes. Some 
attitudes are negative, while others are positive. For example, some golf clubs display a positive way of thinking towards the implementation of EPs: some clubs see EPs as an 'innovative way' to reach a 'wider market' within the Club's 'marketing strategy'. Additionally, some golf clubs believe EPs are 'common sense' that can 'enhance' the golf course and result in 'happier members' and 'visitors'-important issues in customer retention and the generation of new business. This is shown in the following interview extracts:

In the future, we will try and get out to a wider audience. That's our plan...we're trying to find new innovative ways to do this...I can see that...(an EP)...would help with the marketing strategy...it would help reach a wider audience which is our ultimate marketing goal...from a marketing side (GEO OnCourse ${ }^{\circledR}$ ) will be great. Especially, if we can get registered as I think we will be the first one in Wales, to qualify for the accreditation, from that point of view it will be fantastic. To be one of the greenest golf courses in Wales will be great and we will plaster it wherever we can...if we gained the certification I will use it everywhere I possibly could. We'd be a GEO accredited golf course! To say the golf club is a GEO accredited golf club would be awesome for marketing, you couldn't really ask for anything more.

(EPs) are common sense.

(EPs) can enhance the look of the land by planting wildflowers, for example.

By implementing an environmental programme, improves the quality of the golf course, means happier members and visitors.

At the same time, some small golf clubs' owner/managers have negative views on EPs. In particular, they perceive that EPs are not cheap and that there are relatively less expensive and far easier ways that a small golf club can make a profit. This is illustrated in the next interview extracts:

It's not a cheap thing to make everything environmentally friendly.

There are more simple and cost-effective ways that the golf club can make more of a profit (than participate in EPs).

Thus, making EPs cost-effective is a critically important factor in the wider diffusion of such programmes in small golf clubs. This is shown in the next interview quotations:

Making (EPs) cost-effective is the key.

If it's cost-effective and has no extra cost then (the club management committee will) say yes to anything, in terms of our environmental output.

\subsubsection{Awareness of Environmental Impact}

A further factor that undoubtedly influences the uptake of EPs in small golf clubs is that there is a general lack of awareness and understanding on the environmental impacts of golf clubs and the role and significance of EPs among owner-managers and golf members in small golf clubs. This is shown in the next series of interview extracts:

More environmentally aware of your surroundings. It's an educational process, not only for the management but for staff and also for the membership as well.

Over time golfers and staff will become more aware of environmental factors and aware of natural habitats, therefore encouraging and promoting sustainability in golf.

We've got to find ways of making things green and awareness is key.

I'm not sure what these EPs are, so for the golf club to take part in them I would need to know what they are and would need more information about them in the first instance.

Will (EPs) affect the presentation and the playability of the course?

I think the average golfer wouldn't probably know (of EPs).

\subsubsection{Benefits of Implementing EPs}

Without a doubt, another factor that influences the implementation of EPs in small golf clubs is that the real benefits of EPs need to be made clear to owners/managers, committees and members. This is necessary for small golf clubs to feel confident that they are making the right decision to allocate often limited money, time and effort to participate in EPs. This is shown in the following interview extract:

Benefits of EPs must be explained simply to allow members (and committees and greenkeepers) to understand (in order to buy into them). 
Moreover, some small golf clubs perceive that EPs do not really make that 'much difference' to their overall bottom-line/competitive position. The next interview extract demonstrates this:

We had ISO (environmental management programme/standard) and all that sort of stuff and really it doesn't make that much of a difference, to be honest.

\subsubsection{Owner, Manager, Greenkeeper and Club Member Concerns}

An additional factor that clearly influences the instigation of EPs in small golf clubs is the concerns of the owner/manager, greenkeeper and club members. In particular, owner/managers are concerned about whether EPs will affect the presentation and playability of the golf course and require an increase in club membership fees, for example. This is illustrated in the next interview quotations:

Members' attitudes, if course conditions drop, this would be of great concern and also passing on the financial costs (of EPs) to members would be a concern.

You wouldn't get the members supporting the environmental aspect if say for instance the course was in poor conditions.

What is more, owner/managers of small golf clubs are not really concerned about their environmental impacts. In part, because they believe they are in general good for the environment. This is illustrated in the following interview extracts:

People don't realise how much (golf courses) do for the environment.

Golf is actually quite good. I know we get bad press but golf courses are actually being more pro-active in environmental issues...(we have)...an abundance of wildlife.

\subsubsection{Lack of Time, Information and Resources}

A further factor to explain the current low level of implementation of EPs is small golf clubs believe that they do not have the time, information or resources to 'implement', 'maintain', 'monitor', and 'improve' such programmes. This is demonstrated in the following interview extracts:

Having implemented (an EP) for my last organisation as Manager...I am aware of the time, effort and costs involved to gain the required standards to achieve accreditation in these types of management programmes...to implement...a programme costs time and money, and as (the golf club) is run by a voluntary management team and only two part-time administrative staff, I know that unless there is external pump funding available to clubs this project is unlikely to have an urgent impact on the required take up. It is not just about having initial funding to set up but the ongoing funding required to maintain, monitor and improve standards once accreditation has been achieved.

We are a small club of around 100 members and with only two paid staff: a Greenkeeper and a steward. All business work is carried out by me the Secretary and the treasurer on a voluntary basis. It is difficult to find time for what we do now.

It is also very important to recognise that a significant number of small golf clubs are struggling to survive and this is largely due to recent declining memberships across Wales. This is shown in the next interview quotations:

Golf clubs are going through a phase of where it's pure survival at the moment...there are a lot of golf clubs that are on the verge of collapse.

It is a challenging time for golf; club membership levels have steadily decreased throughout Wales during the last few years.

Thus, 'budgets' are very tight for many small golf clubs and consequently, the limited finances that are available tend to be directed towards legal compliance issues, such as, observing regulations on fire safety and disabled access to buildings, rather than implementing an EP. This is illustrated in the following interview extracts:

Budgets are very important.

If we had more time and more finances I'd do a lot more ecology stuff, more black boxes, more beehives, and more that sort of thing.

(The Committee would) rather spend their money on disabled access or fire doors than put money towards helping the club become more sustainable.

\subsubsection{Small Golf Club Characteristics}

An additional factor to explain the current low level of implementation of EPs in small golf clubs is their 
characteristics as regards course management, responsibilities, priorities and locus of control. For instance, small golf clubs generally implement EPs in connection with the management of flora and fauna within Sites of Special Scientific Interest (SSSI) that inhabit the golf course. This is shown in the next interview extract:

Our club does have a minimal environmental programme...We have areas of SSSI.

Furthermore, small golf clubs perceive that their informal EPs are insufficient to gain certification to formal EPs, such as GEO OnCourse ${ }^{\circledR}$ and this may well be one reason why they do not register to the aforementioned programme, as one interviewee said:

We have an environmental programme but not to the level expected (of GEO OnCourse ${ }^{\circledR}$ ).

What is more, EPs currently receive very little, if any, formal attention within the meetings, plans, policies or strategies of management committees in small golf clubs. The next interview extracts shows this:

Very little discussion about environmental strategy.

It is intended to pursue a more rigorous environmental management policy in future...(however, this is not).... top of priority list.

Yet, small golf clubs do realise that their responsibilities include not only the club membership but also environmental stewardship on the golf course. This is demonstrated in the next interview excerpt:

You have a certain responsibility being a committee member so therefore you have a responsibility not only to the membership but also to the environment.

However, an aged and traditional culture and an ever-changing committee in small golf clubs hinder environmental stewardship on the golf course. The next quotes show this:

As a course manager, I have tried to introduce improvements with regards biodiversity. But it's very hard to change the view of a very old, stubborn committee...(I am)...fighting a reluctant committee.

(Moreover, there is a).... continual change of management e.g. secretary, greens committee, whereby attitudes and initiatives regularly change.

\subsubsection{Some Interventions to Support Wider Implementation of EPs in Small Golf Clubs}

A series of interventions emerged from the interviewing with owner/managers that may well influence or accelerate the wider instigation of EPs in small golf clubs. They included some sort of 'penalties', provision of grants, mission statements, green marketing and a stepped or staged approach towards EP implementation. This is demonstrated in the following set of interview excerpts:

Golf's governing body have to put penalties and sort of clauses in place to make sure people do the right thing environmentally.

Do (EPs) open up the possibility for grants?

A well-publicised mission statement so that all...of the membership feel that they have a stake in the process.

You need to publicise (EPs)... whether it's a stamp or a flag or logo on scorecards. You've got to take baby steps (as regards EPs, such as GEO OnCourse ${ }^{\circledR}$ ).

The next section presents the results of the survey on the factors influencing small golf clubs potential employment of EPs.

\section{Survey Results of Influences on the Degree of Implementation of EPs in Small Golf Clubs}

\subsection{Reasons for Small Golf Clubs' Lack of Implementation of EPS}

Table 4. Reasons for the lack of implementation of EPs in small golf clubs $(n=63)$

\begin{tabular}{lcc}
\hline Reasons & Replies & $\%$ \\
\hline Lack of knowledge on environmental programmes *** & 29 & 20 \\
Lack of money *** & 27 & 19 \\
Lack of time ** & 18 & 12 \\
Lack of government funding ** & 17 & 11 \\
Unsubstantiated business case to justify costs (time, money \& effort) * & 10 & 7 \\
Insufficient pressure from members \& guests * & 9 & 6 \\
Insufficient managerial commitment * & 8 & 6 \\
\hline
\end{tabular}


Lack of concern on environmental issues *

Lack of support within golf*

Too much ongoing commitment *

Lack of training opportunities linked to continuing professional development *

Insufficient regulatory pressure *

Too much initial commitment *

Total

\begin{tabular}{cc}
6 & 4 \\
6 & 4 \\
6 & 4 \\
4 & 3 \\
3 & 2 \\
2 & 1 \\
145 & 100 \\
\hline
\end{tabular}

The reasons for small golf clubs' low level of implementation of EPs are given in Table 4. It shows that there are a variety of reasons on why small golf clubs tend not to join EPs. Based on the number replies, these varied reasons can be broken down into most important ***, more important ** and important *. As a result, a 'lack of knowledge of EPs' and a 'lack of money' are the most important reasons for small golf clubs' limited engagement in EPs. Other more important and important reasons include a 'lack of time' and 'lack of government funding' and 'unsubstantiated business case to justify costs', respectively.

\subsection{Small Golf Clubs' Level of Awareness of EPs}

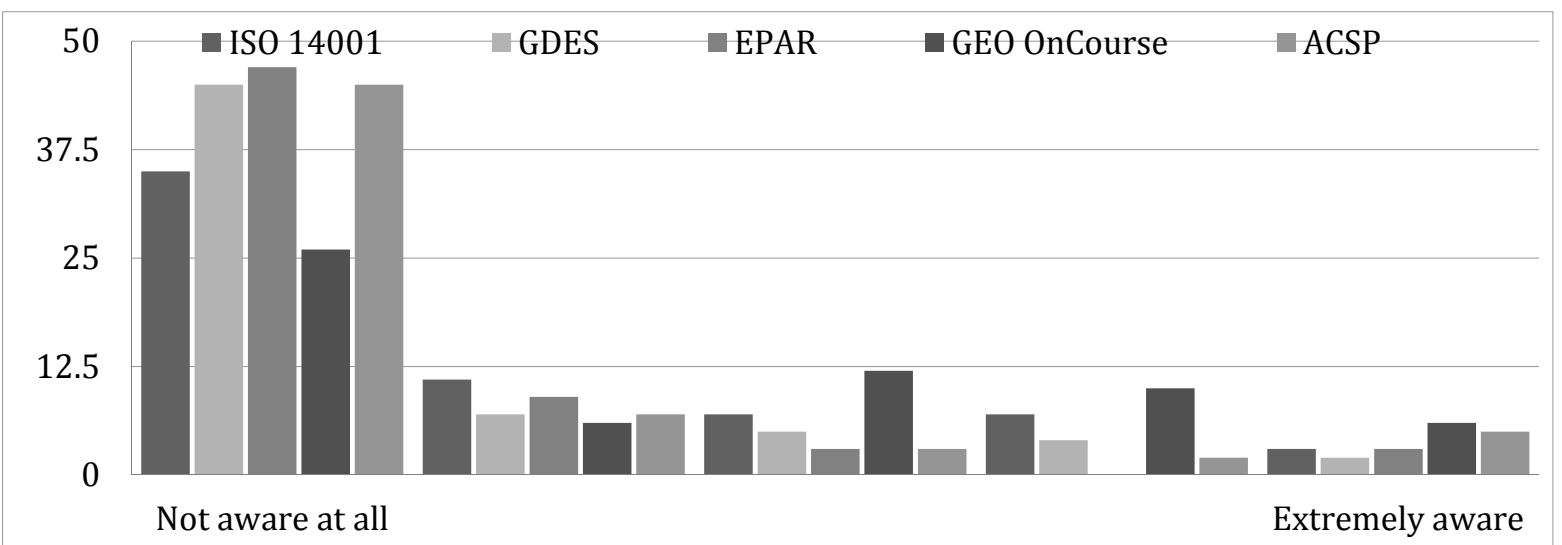

Figure 1. Small golf clubs' level of awareness of EPs $(n=63)$

Small golf clubs' level of awareness of EPs is given in Figure 1. This shows that small golf clubs have a lack of awareness of EPs including bespoke programmes that were developed only for golf clubs and resorts (i.e. E-Par, GEO OnCourse ${ }^{\circledR}$ and Audubon Cooperative Sanctuary Programme (ACSP)) and generic programmes that were designed for all businesses including golf facilities (i.e. Green Dragon Environmental Standard (GDES) and ISO 14001).

\subsection{Small Golf Clubs'Level of Concern and Awareness on Environmental Performance}

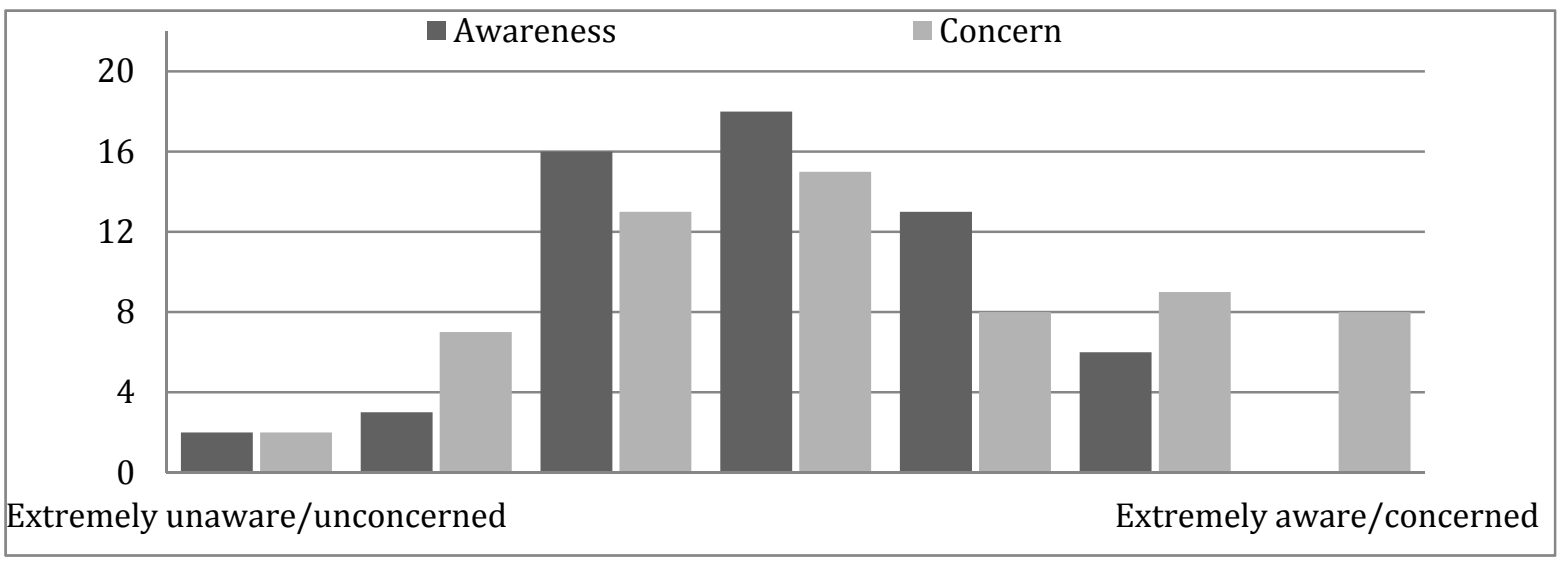

Figure 2. Small golf clubs' level of awareness and degree of concern on their environmental performance $(n=63)$ 
Figure 2 shows small golf clubs' 'degree of awareness' and 'level of concern' on their environmental performance, respectively. It shows that small golf clubs have a moderate degree of concern and awareness of their environmental performance. Interestingly, the above results show that small golf clubs believe they are moderately aware and concerned about their environmental performance (Figure 2). However, this does not translate into a similar degree of awareness of specific EPs (Figure 1). Thus, small golf clubs' level of concern and awareness of their environmental performance may well be overstated.

\section{Discussion}

From the findings of this particular study there would appear to be a number of influences on the level of implementation of EPs in small golf clubs that may also apply to a greater or lesser extent to other sizes of golf facility. They can be broken down into the 'most important', 'more important' and 'important' 'external' (Table 5) and 'internal' (Table 6) influences, respectively. They are discussed below along with a number of interventions that could be employed to increase the uptake of EPs in small golf clubs.

\subsection{External Influences on the Level of Implementation of EPs in Small Golf Clubs}

Table 5. External influences on the level of uptake of EPs environmental in small golf clubs

\begin{tabular}{l} 
External influences \\
\cline { 2 - 2 } $\begin{array}{l}\text { Legislation/regulatory pressure/support *** } \\
\text { Business advantage } * *\end{array}$ \\
Customer demand/satisfaction $* *$ \\
Government policy/grant opportunities and market incentives ** \\
Progressive stakeholders * \\
Sustainability as common business practice * \\
Source: adapted from Spence and Rinaldi (2010). \\
Notes. most important $* * *$ more important $* *$ and important $*$.
\end{tabular}

\subsubsection{Legislation and Regulatory Pressure/Support}

The 'most important' external influence on the level of implementation of EPs in small golf clubs is legislation/regulatory pressure (Spence \& Rinaldi, 2010) since this would clearly significantly increase the wider diffusion of EPs in golf. For example, EPs could become mandatory, rather than a voluntary requirement for golf facilities, as is the case for the UK Food Standard Rating Scheme (Food Standards Agency, 2017). This mandatory scheme helps consumers decide on where to eat out by providing information about the hygiene standards in pubs, cafes, restaurants and golf clubs, for example. Similarly, mandatory EPs would help golfers choose where to play golf by giving them information on the environmental performance and environmental quality of golf clubs. Additionally, enquiries, site inspections, support and communication from governmental regulators on the environmental impacts of golf and environmental legislation affecting golf clubs would help encourage, engage and enable small golf clubs to implement EPs. This, in turn, reinforces the message that EPs are a means to help golf facilities address their environmental aspects, improve and communicate their environmental performance and comply with environmental regulation.

\subsubsection{Business Advantage}

Also, a 'more important' external influence is a business advantage (Spence and Rinaldi, 2010) given that small golf clubs need to see a potentially realisable one in order for them to implement EPs. In particular, they must see clearly defined hard and soft benefits or real value, such as, cost savings and/or increased business opportunities that arise from participating in an EP. One way to address this concern is by the use of case studies that show the real business benefits and short-term wins (Kotter, 2012) that have actually been realised from the successful implementation of EPs in small golf clubs.

\subsubsection{Customer Demand/Satisfaction}

A further 'more important' external influence is real customer demand/satisfaction (Spence and Rinaldi, 2010), from golf club members (as these are the main customers of small golf clubs) and to a lesser extent golf visitors, for greener golf facilities i.e. those that are certified to credible EPs. Developing and implementing new green marketing initiatives could help progress the uptake of EPs in small golf clubs. For example, golf equipment, golf apparel and/or luxury goods manufacturers could sponsor a green golf competition and a golf facility would need to be registered and certified to a trustworthy EP to enter and host such a competition, respectively. This would potentially help get EPs into the hearts and minds of golfers, raise the profile of EPs in the marketplace, and create demand for golf facilities with EPs. This would also help 'create a vision for change' and 
'communicate the vision' (Kotter, 2012) to drive more sustainable golf.

\subsubsection{Policy and Market Incentives}

Another 'more important' external influence to increase the uptake of EPs in small golf clubs is through the provision of grant opportunities and/or tax incentives within governmental policy (Spence \& Rinaldi, 2010). This is necessary, as small golf clubs often have very limited resources at their disposal to apply and embed EPs into their day-to-day management practices. Thus, grants or tax incentives could be considered in support of consultancy fees, for example. In fact, grants were available in this respect for small businesses in Wales to implement the Green Dragon Environmental Standard. This government initiative increased certifications to the standard in small businesses. However, it has since ended, and certifications have as a result significantly declined (Groundwork Trust, 2016). The Green Dragon Environmental Standard adopts a staged approach to implementing an EP, which is modelled on ISO 14001. Registration and certification costs should also be based on turnover so that small golf clubs pay less than golf clubs with higher turnover. In addition, national golf associations should subsidise or provide GEO OnCourse ${ }^{\circledR}$ free to member golf clubs, as is the case in England and Scotland and Portugal, Sweden, and Switzerland, respectively (GEO, 2017b).

\subsubsection{Progressive Golf Stakeholders}

An additional 'important' external influence to stimulate the wider diffusion of EPs in small golf clubs is through progressive golf governors, administrators, trade associations and suppliers (Spence and Rinaldi, 2010). In particular, golf stakeholders that favour and support EPs and sustainable golf. For example, golf's governing bodies, the R\&A (R\&A, 2016) and United States Golf Association (USGA) (USGA, 2016), some golf federations and unions (e.g. International golf federation (IGF, 2018; England Golf, 2018), certain trade associations (e.g. British and International Golf Greenkeepers Association (BIGGA) (BIGGA, 2018), International Association of Golf Tour Operators (IAGTO) (IAGTO, 2018) and GEO (2017b), have been actively developing, promoting and supporting the wider uptake of EMPs. However, so far this support has arguably tended to focus on the most prestigious golf clubs, at the expense of the less high-status, smaller golf club that tends to be involved in leisure golf, at the expense of tournament and tourism golf. Additionally, other golf unions need to be more active in promoting and supporting EPs, such as GEO OnCourse ${ }^{\circledR}$ on their websites, for example. Golf's trade associations, equipment and apparel suppliers, business sponsors and local community could also make more enquiries on the environmental impacts of golf clubs and what steps they are taking to improve their performance. In addition, they could heighten their support for addressing these topics. This would help get EPs on the radar of course management committees within small golf clubs and golf clubs generally.

\subsubsection{Sustainability as a Business Practice}

A further 'important' external influence is that sustainability as a business practice (Spence \& Rinaldi, 2010) needs to be much more recognised, practised and communicated, as a business norm, among all of golf's stakeholders, across golf's whole supply chain. This would then get EPs on the agenda of course management meetings and business plans/strategies within small golf clubs and golf clubs generally. It is also necessary in order to change what golf clubs, think about, feel about, and how they would like to behave as regards environmental governance, stewardship and performance. As one of the study's participants said, 'you've got to change your attitude, you've got to change your culture of how the club is governed, how the club is run'. Thus, golf's key stakeholders need to 'form a powerful coalition' (Kotter, 2012) on sustainable golf. This coalition team would be tasked with creating a sense of urgency, anchoring the changes in golf's culture and building on the change necessary for more sustainable golf (Kotter, 2012). The coalition's leaders would also need to better convince small golf clubs that change management including implementation of EPs is in the interest of not only the larger corporate owned golf tournament facility and golf resort but also the much smaller private and public members' golf club.

\subsection{Internal Influences on the Degree of Implementation of EPs in Small Golf Clubs}

Table 6. Internal influences on the degree of uptake of EPs in small golf clubs

\footnotetext{
Internal influences

Costs for embedding EPs ***

Demographics **

Attitudes towards EPs **

Awareness/understanding of environmental impacts *

Awareness/understanding of EPs *
}

Source: adapted from Spence and Rinaldi (2010).

Notes. most important ${ }^{* * *}$, more important $* *$ and important *. 


\subsubsection{Costs for Embedding EPs}

The 'most important' internal influence on the level of implementation of EPs in small golf clubs is the costs for embedding EPs (Spence \& Rinaldi, 2010) into small golf clubs' day-to-day management practices. This is because small golf clubs generally have limited finances to implement, monitor and maintain such programmes. Thus, public policy and/or market incentives are required in order to help small golf clubs overcome this barrier.

\subsubsection{Demographics}

In addition, a small golf club's demographic profile is a 'more important' internal influence. This is because many small golf clubs are made up of an aged, male dominant demographic profile that is not conducive to change management involving the implementation of EPs (e.g. Kollmuss \& Agyeman, 2012; McKeiver \& Gadenne, 2005). Conversely, women and younger golfers may well be more supportive of small golf clubs' implementation of EPs. Thus, measures should be formulated and implemented to encourage this population to join golf clubs and management committees therein. For example, the UK Equality Act 2010 has given women more rights in golf clubs (The Telegraph, 2011). Moreover, including sustainable golf within a golf club's constitution, development plans, strategy document and mission statement should help ensure that golf clubs continuously engage on environmental performance improvements, regardless of demographics and changing committees.

\subsubsection{Attitudes Towards EPs}

Another 'more important' internal influence is owner/manager attitudes towards EPs (Spence and Rinaldi, 2010). Some owner/managers of small golf clubs have a negative way of thinking towards EPs, primarily because they do not see that there is any real customer demand for such programmes. Indeed, there is currently very limited enquiry from golfers on whether or not golf facilities have any EPs. However, this situation in part arises because golfers are largely unaware of golf's environmental impacts and the role and significance of EPs (Minoli, Goode, \& Metcalfe, 2018; Minoli, Goode, \& Smith, 2015). Yet, golfers show a degree of concern on golf and its relationship to the environment and a level of willingness to promote and support more sustainable golf (Sustainable Golf Project, 2012; Golf Digest, 2008). It is thus encouraging to see that a few owner/managers do have a more positive view of EPs, as they are seen as potentially helpful in small golf clubs' green marketing initiatives for attracting more customers (i.e. golf club members and visitors).

A case in point is the green marketing strategy of Visit Wales as regards Welsh beaches and Blue Flag (Minoli, Goode, \& Smith, 2015). Blue Flag is a voluntary, EP that helps beach visitors decide on what beach to visit by providing information on the environmental quality of a beach. Visit Wales has accordingly been marketing Welsh beaches that have been awarded Blue Flag status, as some of the cleanest in the UK in order to attract more visitors. A similar marketing strategy and slogan could be rolled out for golf clubs that have been certified to credible EPs. This green marketing initiative might well encourage a more positive attitude among small golf clubs' owner/managers towards EPs that may well result in their wider uptake.

\subsubsection{Awareness and Understanding of Golf's Environmental Impacts}

A further 'important' internal influence is that there is a general lack of awareness/understanding of golf's environmental impacts (Spence \& Rinaldi, 2010). This is an important issue given that small golf clubs need to be aware of their environmental impacts and be concerned about them, in order to take steps such as implementing an EP, to mitigate and/or improve this situation. Added to that there is a common belief among small golf owner/managers that golf on balance is actually good for the environment and golf's environmental performance is above average when compared to the environmental aspects of other land use activities, such as housing developments and business parks. As a result, small golf clubs in the main have a lack of awareness/understanding on EPs since they are considered somewhat irrelevant, and consequently, it is not surprising to find that EPs and sustainable golf, are at present seldom mentioned in small golf clubs' business plans/strategies (Anon, 2017). Clearly, small golf clubs need to be aware of their environmental impacts in the first instance in order for them to consider implementing EPs. Designing, implementing and communicating on golf's environmental impacts by means of relevant case studies can be a cost-effective means to address this barrier.

\subsubsection{Awareness and Understanding of EPs}

Another 'important' internal influence is that there is a general lack of awareness/understanding on EPs (Spence $\&$ Rinaldi, 2010). Thus, it is clearly important that education, training, continuing professional development, and degree courses on sustainable golf management including EPs need to be developed and marketed to current and future golf club owners, clubhouse managers and greenkeepers to raise awareness, understanding and 
competency on sustainable golf. For example, Myerscough College, which is affiliated, to the University of Central Lancashire, is one of the few, if not, the only college in the UK to run a degree course in sustainable golf management (Myerscough College, 2018). Similar courses or modules should be developed and/or incorporated into other UK degree programmes on applied golf management. Certainly, there need to be more professional and academic courses on sustainable golf management both in and outside of the UK in order to significantly raise the golf industry's capacity to progress more sustainable golf.

\section{Conclusion}

The study has certain limitations, which do not, however, detract from its ultimate usefulness. The factors that influence the level of implementation of EPs in small golf clubs were investigated using an in-depth exploratory mixed methods case study and the qualitative and quantitative findings of the study are presented in this paper. Several meta-analyses and a particular model and theory were used as a framework to explore and validate the study's findings. The study also focused on a specific geography and type of EP, namely, small golf clubs in Wales, UK as regards GEO OnCourse ${ }^{\circledR}$. Thus, other sizes of a golf facility, another framework, different geographies, and alternative EPs might support, refute or build on the findings and conclusions of this study. Thus, further studies are suggested on this topic that takes account of these variables.

Notwithstanding the study's limitations, this is the first study of its kind to explore EPs from the perspective of small golf clubs. The study primarily provides an important initial insight on the factors that are expected to influence the wider uptake of EPs in golf and offers a conceptual/empirical framework for further studies in this under-researched yet important field. The study should be of value to the golf sector, public policy and all organisations interested in EPs in favour of the greening of small businesses in the greening of an industry for sustainability, with a focus on sustainable golf sport, tourism and leisure.

\section{Acknowledgements}

The author would like to thank the small golf clubs, Marina Schaefer, Gareth Rees, David Thorne and Aidan Metcalfe for their support of this research, which was conducted in Wales, UK.

\section{References}

Ajzen, I. (1991). The Theory of Planned Behaviour. Organisational Behaviour and Human Decision Process, 50, 179-211. https://doi.org/10.1016/0749-5978(91)90020-T

Anon. (2017). Small Golf Club, Strategic Business Plan, 2017/18 to 2021. Personal Communication.

BIGGA. (2018). Ecology and sustainability. Retrieved from https://www.bigga.org.uk/about/membership/benefits/ecology-sustainability.html

Colding, J., \& Folke, C. (2009). The role of golf courses in biodiversity conservation and ecosystem management. Ecosystems, 12, 191-206. https://doi.org/10.1007/s10021-008-9217-1

Company Warehouse. (2016). What is a SME? Retrieved from https://www.thecompanywarehouse.co.uk/blog/2012/07/31/what-is-an-sme/

Darnall, N., \& Sides, S. (2010). Assessing the Performance of Voluntary Environmental Programs: Does Certification Matter? In P. deLeon \& J. E. Rivera (Eds.), Voluntary Environmental Programs (pp. 213-238). Lanham: Lexington.

England Golf. (2018). Greener golf - sustainability. Retrieved from https://www.englandgolf.org/page.aspx?sitesectionid=2594\&sitesectiontitle $=$ Greener+Golf +-+ Sustainabilit $\mathrm{y}$

Federation of Small Businesses. (2007). Social and environmental responsibility and the small business owner. Retrieved from http://www.fsb.org.uk/LegacySitePath/policy/assets/CSR\%20Dec\%202008.pdf.

Food Standards Agency. (2017). Frequently asked questions about the food hygiene rating scheme. Retrieved from https://www.food.gov.uk/multimedia/hygiene-ratingschemes/ratings-find-out-more-en/fhrs

GEO. (2017a). Directory. $\quad$ Retrieved from https://www.golfenvironment.org/directory?country=United+Kingdom\&gb_country $=4 \&$ us_state $=\&$ ca_province $=\&$ category

GEO. (2017b). GEO Foundation update and new OnCourse officially launched. Personal Communication.

Golf Digest. (2008). Golf and the environment: Golfer perceptions and attitudes concerning the game and its relationship with the environment. Retrieved from http://www.golfdigest.com/images/magazine/2008/05/ 
golfandtheenvironment_study2008.pdf

Groundwork Trust. (2016). Green Dragon Environmental Standard. Presentation, at Cardiff Metropolitan University, Cardiff, December 2016.

Hillary, R. (2004). Environmental Management Systems and the Smaller Enterprise. Journal of Cleaner Production, 12(6), 561. https://doi.org/10.1016/j.jclepro.2003.08.006

Hillary, R., \& Burr, P. (2011). Evidence-based study into the benefits of EMSs for SMEs. London: Department of Environment and Rural Affairs.

IAGTO. (2018). Sustainability Awards. $\quad$ Retrieved from https://www.bigga.org.uk/about/membership/benefits/ecology-sustainability.html

IGF. (2018). Sustainability. Retrieved from https://www.igfgolf.org/about-igf/sustainablity/

ISEAL Alliance. (2017). Full members. Received from https://www.isealalliance.org/our-members/full-members

ISO. (2015). Introduction to ISO 14001: 2015. Retrieved from https://www.iso.org/files/live/sites/isoorg/files/archive/pdf/en/introduction_to_iso_1 4001.pdf

Johnson, M. P., \& Schaltegger, S. (2016). Two Decades for Sustainability Management tools for SMEs: How far have we come? Journal of Small Business Management, 54(2), 481-505.

Kishimoto et al. (2016). The long-term association between physical activity and risk of dementia in the community: the Hisayama Study. European Journal Epidemiology, 31, 267-274. https://doi.org/10.1007/s10654-016-0125-y

Kollmuss, A., \& Agyeman, J. (2012). Mind the gap: why do people act environmentally and what are the barriers to pro-environmental behaviour? Environmental Education Research, 8(3), 239-260. https://doi.org/10.1080/13504620220145401

Kotter, J. P. (2012). Leading Change. Boston: Harvard Business Review Press.

McKeiver, C., \& Gadenne, D. (2005). Environmental Management Systems in Small and Medium Businesses. International Small Business Journal, 23(5), 513-537. https://doi.org/10.1177/0266242605055910

Minoli, D. M., \& Smith, M. T. (2011). An Exploration of Golf and Voluntary Environmental Programmes. Journal of Environmental Planning and Management, 54(7), 871-889. https://doi.org/10.1080/09640568.2010.539372

Minoli, D. M., Goode, M. M. H., \& Smith, M. T. (2015). Are Eco-Labels Profitably Employed in Sustainable Tourism? A Case Study on Audubon Certified Golf Resorts. Tourism Management Perspectives, 25, 207-216. https://doi.org/10.1016/j.tmp.2015.07.011

Minoli, D. M., Goode, M. M. H., \& Metcalfe, A. W. (2018). Are Sport Tourists of an Environmental Mindset to Drive the Green? The Case of Golfers. Tourism Management Perspectives, 25, 71-79. https://doi.org/10.1016/j.tmp.2017.11.007

Myerscough College. (2018). MA Sustainable Golf Course Management On-Line. Retrieved from https://www.myerscough.ac.uk/courses/sportsturf/ma-sustainable-golf-course-management-on-line/

Parker, C., Redmond, J., \& Simpson, M. (2009). A Review of Interventions to encourage SMEs to make Environmental Improvements. Environment and Planning C: Government \& Policy, 27(2), 279-302. https://doi.org/10.1068/c0859b

Peattie, K. (2005). Wales and sustainable development: Reference compendium. [Project Report]. Cynnal Cymru/Cambridge Programme for Industry. Retrieved from http://www.gci.org.uk/Documents/Wales_and_Sustainable_Development_Reference_Compendium_Englis h.pdf

Porter, M. (1998). Competitive Advantage: Creating and Sustaining Superior Performance (2nd ed.). New York and London: Free Press. https://doi.org/10.1007/978-1-349-14865-3

R\&A. (2015). Golf around the world 2015. St Andrews: R\&A.

R\&A. (2016). Sustainability. Received from http://www.randa.org

R\&A. (2017). Sustainable Management of Golf Courses. Retrieved from http://www.surrey-bigga.co.uk/downloads/Sustainable_management.pdf

Reid, L., \& Hunter, C. (2013). In R. Coles \& Z. Millman (Eds.), Landscape, Well-Being and Environment. 
London: Routledge.

Russell, P. (2015). R\&A, Presentation on Sustainable Golf. Sustainability Roadshows, Wales, UK. Newport: Golf Union of Wales.

Schaper, M. (2001). Environmental Attitudes and Practices amongst Small Business Owners/Managers in the Western Australian Community Pharmacy Sector. Retrieved from https://espace.curtin.edu.au/bitstream/handle/20.500.11937/10338/19702_downloaded_stream_220.pdf?seq uence $=2 \&$ isAllowed $=\mathrm{y}$

Schot, J., Brand, E., \& Fisher, K. (1997). The Greening of Industry for a Sustainable Future: Building an International Research Agenda. Business Strategy and the Environment, 6, 153-162. https://doi.org/10.1002/(SICI)1099-0836(199707)6:3<153::AID-BSE109>3.0.CO;2-Y

Spence, L. J., \& Rinaldi, L. (2010). Sainsbury's: Embedding Sustainability within the Supermarket Supply Chain. In A. Hopwood, J. Unerman, \& J. Fries (Eds.), Accounting for Sustainability: Practical Insights (pp. 47-72). London: Earthscan.

Sport Industry Research Centre. (2016). A Satellite Account for Golf in the UK. Sheffield Hallam University: Sport Industry Research Centre.

Sustainable Golf Project. (2012). The value of sustainable golf: Survey results on golfers' attitude towards sustainability. Retrieved from http://www.sustainablegolfproject.com/documenten/13092012\%20Sustainable\%20Golf\%20Project\%20-\%2 0Golfers\%20Survey.pdf

The Greening of Industry Network. (2018). The Greening of Industry Network: Research and Policy for a Sustainable Future. Retrieved from http://www.greeningofindustry.org

The Telegraph. (2011). Lady golfers unhappy about the law to end sex discrimination. Retrieved from https://www.telegraph.co.uk/news/newstopics/howaboutthat/8320250/Lady-golfers-unhappy-about-law-to-e nd-sex-discrimination.html

United Nations Industrial Development Organisation (UNIDO). (2011). UNIDO Green Industry Initiative for Sustainable Development. Received from https://www.unido.org/fileadmin/media/documents/pdf/Energy_Environment/Green_Industry/Green\%20In dustry\%20Initiative\%20for\%20Sustainable\%20Industrial\%20Development.pdf

USGA. (2016). Water Resource Centre. Retrieved from http://www.usga.org/content/usga/home-page/course-care/water-resource- center.html

Welsh Assembly. (2009). One Wales: One Planet - The Sustainable Development Scheme of the Welsh Assembly Government. Retrieved from http://www.assembly.wales/Laid\%20Documents/GEN-LD7521\%20- \%20One\%20Wales\%20One\%20Plane t\%20- $\quad \% 20$ The\%20Sustainable\%20Development\%20Scheme\%20of\%20the\%20Welsh\%20 Assembly\%20Government-22052009-130462/gen-ld7521-e-English.pdf

Welsh Golf Union. (2016). Welsh Golf Club Survey 2015/16. Retrieved from http://www.golfunionwales.org/documents/general/guw-survey-2016-6795.pdf

Welsh Golf Union. (2017). Greener Golf. Retrieved from http://www.walesgolf.org/greener-golf/

Yin, R. K. (1984). Case study research: design and methods (2nd ed.). London: Sage.

\section{Copyrights}

Copyright for this article is retained by the author, with first publication rights granted to the journal.

This is an open-access article distributed under the terms and conditions of the Creative Commons Attribution

license (http://creativecommons.org/licenses/by/4.0/). 